\title{
Microorganisms and Mankind - The Ongoing Battle
}

\author{
SHIKHAR JAIN \\ Department of Pediatrics and Neonatology, Choithram Hospital and Research Center, \\ Indore (MP) 452 001, India. scjain45200@yahoo.co.in
}

$\mathrm{M}$ icroorganisms evolved before man and they are assimilated into and form an integral part of his environment and body. They reside in skin, oral cavity, gut and parts of respiratory and genitourinary tract. As commensals, they assist many body functions and also prevent invasion by pathogenic organisms. However, these usually non-pathogenic organisms may turn pathogenic under some circumstances like poor host immunity and cause life-threatening infections [1]. Organisms may gain access to body from air, water, earth, or direct or indirect contact with man, animals, contaminated food, fomites, articles and hands. When this occurs in community environment it is called community acquired infection. Public health measures and individual practices of hygiene, asepsis, wearing masks and hand washing are principal preventive steps invented initially. However, defaults in these are still the most important causes of wide spread infections.

As modern medicine developed, hospitals and special care areas grew, we had areas with more pathogenic microbes likely to be transmitted more easily to more susceptible people. The hospital-acquired or nosocomial infections [2] were controlled by strategies involving hospital waste disposal, barrier nursing, isolation, universal precautions and antibiotics. As medicine became more intensive seeking to salvage sicker and weaker, it became more invasive. Electively bypassing or breaching natural body barriers for IV infusion, medications, intubations, mechanical ventilation (MV), catheterization, and monitoring became a routine. Ongoing meticulous aseptic precautions for these invasive procedures became very important. Invasion was measured in terms of hospital days, catheterisation hours, number of invasion episodes and so on. The term healthcare associated infections (HAI) got its root [3].

Even 'non invasive' procedures like touch, temperature record, oral suction, drugs including gastric acid suppressants, and antibiotics are actually invasive in very sick and weak like preterm babies as these invade protective microenvironment or damage natural barrier. Antimicrobials need special consideration as they are discredited for emergence and preferential survival of resistant organisms, currently a dreaded situation. The resistant organisms have seeped into the community environment (Chitnis D, Unpublished data) and have been found colonising normal newborns also [4]. With increasing home/community care for chronic diseases, early discharge protocols and frequent admissions, the distinctions between hospital, and community-acquired infections have gotten somewhat blurred [5]. Thus, we have a changing scenario (battlefield) and dynamic situation of ongoing fight between microbes and man and we do not see an end to it in near future. A permanent or a path breaking new solution is also not in sight.

The epidemiology, risk factors, organisms and outcome are different in subsets of patients and hospital areas. The characteristics are typical and similar, though variable, in neonatal intensive care units (NICU) around the world. In this issue of Indian Pediatrics, Bolat, et al. [6] in a carefully planned study of HAIs in a NICU in Turkey, have confirmed what is known and what can be suspected. The incidence of HAIs ( $16.2 \%$ in their study), is high and so is mortality (17.3\%). Invasive procedures like vessel catheterization, mechanical ventilation, and parenteral nutrition significantly increased risk of infection, more so in immune-compromised babies with lower weights, asphyxia, or antenatal steroids. Commensal organisms like coagulase-negative staphylococcus $(25.5 \%)$ and candida (2.9\%) were common isolates and antibiotic resistance prone organisms like Klebseila (9\%), coagulase-positive staphylococcus (6.8\%), Enterobacter (5.4\%), Acinetobacter (4.7\%) and Pseudomonas (1.1\%) also prevailed. Blood stream infections (BSI) were commonest $(66.7 \%)$ followed by ventilator associated pneumonia (16\%) and catheter related BSI (14.7\%).

Prevention appears to be the primary strategy of choice currently [7]. Simple individual hygienic measures including hand washing and use of antiseptic rub before and after touching babies should be followed by all staff from consultants to class IV. Units should be well lighted, ventilated, not crowded and with free running water supply. Good housekeeping and equipment 
disinfection protocols must be adhered to. Special attention should be given to resuscitation bags, suction, oxygen and humidification apparatus. Care of IV lines and catheters and precautions during each invasion episode like intubation, suctioning and IV injections (care bundles) is important [8,9]. Admission criteria to NICU need to be stringently defined. The number of injections, IV lines, suction and other invasions in a baby should be minimized. We must encourage early enteral feeds with human milk. A regular surveillance system is likely to open our eyes to defaults and deficiencies. Wide gaps between our knowledge and implementation exist and we have to pay attention to implementation strategies. Any break or weakness in the prevention chain can be easily taken advantage of by microbes who are natural experts in guerrilla warfare - they lie low in unfavourable circumstances, adapt and attack at any opportunity. Long term solution appears to lie in promoting healthy ways of living and augment harmony with biological nature and its forces. What it actually means in term of actions is a matter of thought and study.

Competing interest- None stated; Funding:Nil.

\section{REFERENCES}

1. Famurewa O. Microbes and Man: The endless battle. 2001. Available from: www.nuc.edu.ng/nucsite/file/ils\%202110/ ILS\%202001/ILS-44.pdf. Accessed on 29 June, 2012.
2. Sohn AH, Garrett DO, Sinkowitz-Cochran RL, Grohskopf LA, Levine GL, Stover BH, et al. Prevalence of nosocomial infections in neonatal intensive care unit patients: Results from the first national point-prevalence survey. J Pediatr. 2001;139:821-7.

3. Raju U, Dayal SS. Nosocomial infections in the NICU. In: Gupte S, editor. Recent Advances in Pediatrics, special vol 21. Delhi: Jaypee Publications; 2011.p.221-36.

4. Verma S, Jain K, Chitnis D. Rectal swabs from neonates and mothers for presence of multidrug resistant bacteria. NBE thesis 2011, Choithram Hospital \& Research Center Indore.

5. Leng R, Leal JR, Church DL, Gregson DB, Ross T, Laupland KB. The distinct category of health care associated blood stream infection. BMC Infectious Diseases. 2012;12:85.

6. Bolat F, Uslu S, Bolat G, Comert S, Can E, Bulbul A, et al. Healthcare-associated infections in a neonatal intensive care unit in Turkey. Indian Pediatr. 2012;49:951-7.

7. Adams-Chapman I, Stoll BJ. Prevention of nosocomial infections in the neonatal intensive care unit. Curr Opin Pediatr. 2002;14:157-64.

8. O'Grady NP, Alexander M, Dellinger EP, Gerberding JL, Heard SO, Maki DG, et al. Guidelines for the prevention of intravascular catheter-related infections. Pediatrics. 2002;110:e51.

9. Pronovost P, Needham D, Berenholtz S, Sinopoli D, Chu $\mathrm{H}$, Cosgrove $\mathrm{S}$, et al. An intervention to decrease catheterrelated bloodstream infections in the ICU. N Engl J Med. 2006;355:2725-32.

\title{
Secondary Cigarette Smoke Causes DNA Damage: Susceptibility for Disease Development
}

\author{
Basu Dev BanerJee ANd SMita JaIN \\ Environmental Biochemistry and Molecular Biology Laboratory, \\ Department of Biochemistry, University College of Medical Sciences, University of Delhi, \\ and Guru Teg Bahadur Hospital, Delhi, India. \\ banerjeebd@ucms.ac.in
}

$\mathrm{E}$ xposure to secondary cigarette smoke, also called environmental tobacco smoke (ETS) or second hand smoke occurs when a person (non-smoker) encounters smoke either produced from burning cigarette or exhaled from smoker. ETS is a significant health problem in children worldwide. Cigarette smoke inhalation causes cancer in various organs and smoking during pregnancy harms both mother and baby, initially retarding intrauterine development with several side-effects [1]. Various respiratory diseases such as asthma and bronchiolitis can be seen in children, even at low-level exposure to environmental cigarette smoke $[2,3]$. Cigarette smoke contains several reactive oxygen species (ROS) which may damage lipids, proteins, DNA, carbohydrates and other biomolecules. Most ROS have a short half-life and cause damage locally except $\mathrm{H}_{2} \mathrm{O}_{2}$ which has a relatively long half-life and can travel long distances causing DNA damage at distant sites. Increased production of ROS leads to an imbalance between the oxidative forces and the antioxidant defence systems, favoring an oxidative stress or injury. ROS can influence cell survival and genomic stability. 